\title{
The financial performance of the health care industry: A global, regional and industry specific empirical investigation
}

\author{
Gregor Dorfleitner, Felix Rößle \\ University of Regensburg, Department of Finance, 93040 Regensburg, Germany
}

This version: June 27, 2016

\begin{abstract}
This article analyses the financial (out-) performance of all listed health care companies. The health-care sector outperforms the market in the period from 2000 to June 2015. The performance is driven by companies from Americas and Asia as well as companies from the pharmaceuticals sub-segment. Additionally, bull periods appear to be the main driver for the outperformance. Eurobased investors can expect different outcomes of their investments to those of USD investors. However, the main trends remain unchanged.
\end{abstract}

Keywords: stock performance, four-factor model, health economics

*Corresponding author: e-mail: gregor.dorfleitner@ur.de, Tel: +49-941-943-2684, Fax: +49-941$943-812683$ 


\section{Introduction}

The health-care sector is amongst the largest sectors worldwide. In many developed countries, annual spending on health care exceeds $10 \%$ of GDP, totaling a global spending amount of more than 7 trillion USD in 2015. In addition to the current size, the Economist Intelligence Unit forecasts future growth rates for health care above GDP and population growth. ${ }^{1}$ Companies included in the health-care sector comprise activities related to the supply of health care services, supply of technology and equipment as well as pharmaceuticals, biotechnology, and medical research. Each industry had different dynamics. Investments in this sector are affected by many variables, including positive trends related to demographics.

There are many assumptions and expectations with regards to health care investments. First, the business grows due to demographics. Second, as health care spending increases with rising wealth, growth should be driven by emerging markets. Third, the high labor insensitivity business models are expected to decline, whereas technology driven business models are on the rise. Fourth, generic drugs are replacing new drugs with high development costs. Fifth, patients are dependent on medicine even in economically bad times and therefore investments are particularly crisis proof compared to other investments. The goal of this article is a broad overview on investments in the health-care sector from several perspectives, addressing the above-mentioned assumptions and expectations.

The literature on health care is generally very extensive. Naturally, there is a huge body of literature in the field of natural sciences and medicine, as well as in the field of combining business and medicine. However, literature covering the financial performance of health-care investments is scant. To the best of our knowledge, there is only one study that covers the performance of

\footnotetext{
${ }^{1}$ For more details see http://www.eiu.com/industry/Healthcare.
} 
health care investments in detail (Trsel et al. (2014)). Moreover, few studies focus on very special topics in health care performance (e.g., Bredthauer et. al. (2015)), and several studies include health care among several branches in their samples (e.g., Fama and French (1997), Hong et al. (2007)).

Trsel et al. (2014), the only study focusing solely on health care, examines the sector from an US view in a long term empirical analysis from 1926 to 2009. According to their data, health care stocks have generated economically significant risk-adjusted returns in the region of $1.8 \%$ to $3.5 \%$, annually. In addition, health care investments have provided a lower correlation with the market. For a 25-year period ending December 2009, health care stocks had a correlation of 0.7 with the broad market, lower than that of any of the other industries the authors examine. Bredthauer et al. (2015) investigate the performance of the US health care industry with a special focus on the presidential administration's political party and the Federal Reserve's monetary policy. In their 60-year time period from 1954 to 2013, Bredthauer et al. (2015) find significantly positive alphas. The health care industry experienced positive abnormal returns during contractionary monetary regimes and when a Republican was president during expansionary monetary regimes. After 1985, Democratic administrations and contractionary monetary regimes have coincided with positive health care returns, as have Republican administrations and expansionary monetary regimes. Guirguis et al. (2001) analyze 223 health care IPOs during 1985 and 1996. They find a statistically significant outperformance to the market, but no statistically abnormal returns for IPOs relative to matched control firms.

As mentioned above, there are several studies covering multiple branches, also including health care investments in their samples. The most famous example is Fama and French (1997). Using the capital asset pricing model and the Fama and French three factor model, the authors analyze 48 industries, of which three are related to health care in a period from June 1968 to 1994. 
In both models, the three portfolios show positive alphas, but only pharmaceutical products and medical equipment show a significant outperformance in the three factor model. Hong et. al. (2007) present various industry portfolios. The international (non US) health-care portfolio exhhibits a positive mean return of almost 1\% per month over a period from 1973 to 2002. Dellva et al. (2001) analyze Fidelity Sector Mutual Funds from 1989 to 1998. In their sample, the Fidelity Select Health Care mutual fund can also be found. They conclude that the health care fund was one of the funds that outperformed the S\&P 500.

The literature analysis demonstrates a gap in research. The existing studies indicate that there is an outperformance of the health-care sector. However, further details are missing. The aim of this article is to close this gap in research. We are the first to study the health-care sector in more detail. In particular, we are the first to study a large global sample of more than 3,600 companies. We are also the first to compare the industry on a regional basis as well as looking beneath the surface and analyzing sub-groups in the health-care sector. In taking into consideration the most recent research on performance evaluation (e.g., Nofsinger and Varma (2014)), we are also the first to analyze the performance in different market states. Most performance studies are purely based on USD returns. In addition to the standard approach, we are the first to shed light on the performance of the health-care sector in another currency.

Our results can be summarized as follows. The health-care sector outperforms the market in a period from 2000 to June 2015 . The performance is driven by companies from the Americas and Asia as well as companies from the pharmaceuticals sub-segment. Bull periods are the main driver for the outperformance. Investors that are based in the Euro area can expect divergent outcomes with regard to their investments to a USD investor. However, the main trends remain unchanged.

The next sections are structured as follows: In Section 2 we provide a detailed insight into our data, the construction of the portfolios and the methodology used in our analysis. Section 3 
presents our results, and Section 4 presents some robustness tests: In the last section we present various concluding remarks.

\section{Data and Methodology}

To investigate the financial performance of the health-care industry around the world, we analyze value-weighted portfolios of health-care stocks. The companies are identified by industry codes, which is a standard approach in finance (e.g. Fama and French (1997)). As we target a global sample, we use the Thomson Reuters business classification codes for our analysis. ${ }^{2}$ All public listed companies, regardless of size, age, origin, etc. which are part of the health-care sector (Thomson Reuters sector sectors code 56) are added to our list. We also include all dead companies to avoid a survivorship bias. Our total sample consists of 3,680 companies, or, in other words, all listed health-care stocks. In addition to the company names, we also collect information upon the sub-industries and the origin of each company.

In order to build our health-care portfolios, we take monthly total return data (including dividends) as well as the market capitalization for each company from Thomson Reuters Datastream. All data are converted into USD. The valuation is based on the market capitalization of the companies at the previous month's end. Compared with a pure analysis of funds or indices, the rather complicated process of building the portfolios gives us the unique opportunity to analyze the sample from various perspectives. We form our monthly rebalanced value-weighted portfolios for a global, four regional (Americas, Asia, Australia, Europe) and four sub-sector samples (biotechnology and medical research, health-care equipment and supplies, health-care providers and services, and pharmaceuticals) in the health care industry. As a market benchmark,

\footnotetext{
${ }^{2}$ Previous studies on health care use the SIC (Standard Industrial Classification) codes for their stock selection. As our analysis is global, we cannot use a code that is only available for US companies.
} 
we use global and regional MSCI Indices. The data is also taken from Datastream. The global and regional factors for SMB, HML and WML for the Carhart (1997) four-factor model are extracted from Andrea Frazzini’s database.

Table 1 presents summary statistics for the global health-care portfolio including the number of firms, the number of dead firms and the average monthly return for the full-sample period from 2000 to June 2015.

(Table 1 about here)

Table 1 already provides some interesting information about the sample. The total sample consists of 3,680 companies from all over the world. All companies are combined in a single value-weighted portfolio. The positive return of $0.73 \%$ per month during the full observation period of more than 15 years proves that investors were able to generate a positive outcome of their investment in global health-care stocks.

To provide a first impression of the financial performance of the health-care sector, Figure 1 illustrates a 100 USD investment in the portfolio of the global health-care sector and the market benchmark in the period from January 2000 to June 2015. Within the first eleven years, the healthcare portfolio performs slightly better but, nevertheless, relatively similarly to the market benchmark. However, from 2011 onwards, the global health care companies outperform the market. At the end, the investment in the market increased to approximately 180 USD, while the investment in the health-care portfolio more than tripled, growing to approximately 345 USD. These findings indicate that there could be differences between the health-care firms and the market in terms of financial performance. 
(Figure 1 about here)

\section{Time Series Factor Regression Tests}

We use the Carhart (1997) four-factor model to analyze our portfolio. It is an extension of the Fama and French $(1992,1993)$ three-factor model and the capital asset pricing model, which is based on Sharpe (1964), Lintner (1965) and Mossin (1966). The four-factor model is widely used in financial literature and allows us to compare our results with those of prior studies.

To take into consideration the latest research on performance evaluation, we study different market states (e.g., Nofsinger and Varma (2014)). During the sample period from January 2000 to June 2015, we recognize two bear phases in the stock market based on the peak and trough of the MSCI World Index. The first bear period covers the period from March 2000 to October 2002 and is regarded as the burst of the technology bubble. The second bear period is from October 2007 to March 2009 and represents the global financial crisis. These periods for our international sample are identical to the bull and bear periods identified by Nofsinger and Varma (2014) for the United States and to Lesser et al. (2016) for the global market.

Our outlined measurement framework translates into the following monthly time-series factor regression equation:

$$
R_{i}-R_{f}=D_{B u l l} a_{B u l l}+D_{B e a r} a_{B e a r}+b_{i} M K T+s_{i} S M B+h_{i} H M L+w_{i} W M L+e_{i},
$$

The regression describes the Carhart (1997) four-factor model. In the regression, $R_{i}-R_{f}$ is the monthly excess return of health-care portfolio $i$ and $M K T$ is the monthly excess return of the market benchmark and $R_{f}$ corresponds to the monthly U.S. T-Bill rate. The symbols $a_{B u l l}$ and $a_{\text {Bear }}$ represent the alpha estimates measuring out- and underperformance in bull and bear periods, respectively, and $D_{\text {Bull }}\left(D_{\text {Bear }}\right)$ is a dummy variable that takes the value of one during 
bull (bear) months and zero otherwise, while $e_{i}$ is the regression residual. The factors SMB, HML and WML are, respectively, the returns on the explanatory factors related to size, value and momentum: SMB (small minus big) is the return difference between portfolios of small and big stocks in terms of market capitalization, HML (high minus low) is the return difference between portfolios of high and low book-to-market stocks and WML (winners minus losers) is the return difference between portfolios of stocks with high and low prior twelve-month returns. All factors are obtained from Frazzini's data library. ${ }^{3}$ The statistical significance of all estimates is derived from Newey and West (1987) robust standard errors. Fama and French (2012), as well as Griffin (2002), find that size, value and momentum factors are country-specific and that global models are not successful in explaining average returns on regional size-value or size-momentum portfolios. Therefore, we use global factors only to explain global portfolios, and regional factors to explain regional portfolios.

\section{Results}

Table 2 presents alpha estimates and characteristics of the portfolio of the health-care stocks based on the factor sensitivities relative to the explanatory factors of the Carhart (1997) four-factor model over the sample period from 2000 to June 2015.

(Table 2 about here)

Our four-factor model results reveal that the global health-care portfolio outperforms the market in the period from 2000 to June 2015. By controlling for size, value and momentum, we

\footnotetext{
${ }^{3}$ Andrea Frazzini’s data library is accessible via http://www.econ.yale.edu/ af227/data_library.htm.
} 
find an alpha estimate of $0.36 \%$ per month or $4.32 \%$ per year, which is significantly different from zero. Sample 1 also shows that the health-care stocks are less risky than the market. In addition, we observe a negative sensitivity towards the SMB factor, which can be explained through the nature of the portfolio. There is a large number of small stocks included in the sample, but due to the value weighting of the portfolio, the large caps have a high influence on the total portfolio.

When considering the regional sample, we observe different results for the four regions. While the Americas and Asia both outperform their regional benchmark on a significant basis, Australia and Europe do not exhibit alpha estimates that are statistically different from zero. The finding for the Americas sample is in line with previous literature (e.g. Trsel et al. (2014)), which observes an outperformance of US stocks, which represent the vast majority in our Americas sample. Just like the the global sample, the regional health care samples also show betas below one. This is reasonable and in accordance with the expectations that are usually combined with health care investment.

Sample 3 reports the results of the industry specific four-factor model regressions. The main finding is the outperformance of the pharmaceutical stocks. The three other health-care portfolios, being biotechnology \& medical research, health care equipment \& supplies and health care providers \& services all have positive alphas, but they are not significantly different to zero. To sum up, after controlling for size, value and momentum, we find an outperformance for the global portfolio, which appears to be driven by stocks from Americas and Asia as well as by stocks from the pharmaceuticals industry. We do not find any negative alphas.

Previous literature argues that the financial performance may vary during different market states (e.g., Nofsinger and Varma (2014)). Thus, we separately investigate bull and bear alpha estimates. In particular, stocks of the health-care sector are believed to be more resistant against a crisis, as many people depend on medical service and certain drugs and therefore impose a 
certain degree of demand regardless of the economic situation. Table 3 illustrates the alpha estimates during both market conditions, using the performance evaluation model.

(Table 3 about here)

Moving towards the different market states reveals a different picture to that of the overall period. We observe no significant alpha estimates in the bear periods in any of the samples. However, we observe significant alphas in bull periods for the global sample as well as for all regional and the pharmaceuticals samples. This result is of particular interest as many believe that health-care stocks are especially resistant in times of economic downturn and therefore outperform the market in bear periods. Our results suggest that the overall health care market neither outperforms nor underperforms in bear periods. This could be attributed to the fact that large parts of health-care spending is government-related. In phases of economic downturn, spending on health care equipment (e.g. in hospitals) is often also reduced and health-insurance companies require their customers to use generics instead of highly-priced original drugs. However, we find an outperformance for the global portfolio as well as for the regional portfolios in bull periods, driven by the pharmaceuticals sample. This could be caused by the fact that during economically strong periods, especially in the strongly growing developing markets, more and more people can afford health-care services of all kinds and governments are less dependent on reducing spending on health care.

Most academic studies covering the performance of stocks, funds or indices only analyze returns based on USD. However, a large set of investors is located outside the US and their investment result depends on the outcome in the local currency. Therefore, we additionally analyze our portfolios from a European investor's perspective. The results are presented in Table 4. 
(Table 4 about here)

Our Euro-based four-factor model results reveal that the global health-care portfolio outperforms the market in bull periods. This result is statistically significant on the $5 \%$ level and in line with the USD results shown in the previous tables. For the bear period, we find no significant performance difference between the global portfolio and the benchmark, which is also consistent to the USD result. For the total period, however, we do not find an outperformance. When considering the regional sample we observe different results with respect to the bull periods. While we find a trend towards positive outcomes in bull periods for all samples, only the Asian, Australian and European portfolios outperform on a significant level. After controlling for size, value and momentum, the Americas sample does not outperform on a significant level in the bull period anymore. The results for the bear periods are similar to our previous results, as we find no alpha estimates that are significantly different to zero. Regarding the total period, only the Asian sample outperforms. A look at sample 3 reveals that only the health care equipment and supplies industry sub-portfolio outperforms on a $10 \%$ level in the bull period. Besides the pharmaceuticals portfolio in the bear period, all other portfolios demonstrate an outperformance in the bear period and the full period, albeit not a statistically significant one. The results prove that after controlling for size, value and momentum, investors can expect different results from their investment if they base their investment result on a currency other than USD.

\section{Robustness}

The results of any performance study heavily depend on how the data sample and the portfolio are complied as well as the timeframe used. Black (1993) describes such a scenario. To avoid any biases, we use the most comprehensive method of building a sample, as we include every available company in our sample, even considering now-dead companies. In the previous 
analysis, we used the market capitalization of each company to construct our portfolio. However, there are also other methods used to build a portfolio that can be implemented to test the robustness of the results. Academics often apply an equal weighting of the included company returns. Even though this approach has the disadvantage that we have to exclude some companies such as penny stocks that are very volatile and would affect our results, we still choose to implement this method. Table 5 presents the results after having excluded all companies with a market cap of less than USD 500 million. In addition to the value weighting and the equal weighting, we also consider a value-weighted version of our portfolio that is controlled for liquidity. We perform this analysis, because some of our stocks are small caps or even penny stocks and this procedure puts more emphasis on real investability. Moreover, it is not possible or at least difficult to invest in some of the companies. Therefore, we exclude all companies whose trading volume is less than $20 \%$ of the available shares per month. The results of this second test are also presented in Table 5.

(Table 5 about here)

Table 5 presents alpha estimates for the full period as well as for the bull and the bear periods of the equal-weighted and liquidity-adjusted regressions. The table shows that our results for the global health-care investments are generally robust with respect to the addressed modifications. Like in Table 2 and Table 3, we find an outperformance of the global portfolio in the full period as well as in the bull period, whereas we observe no significant alpha estimates in the bear period. This result is valid for both the equal-weighted portfolio and the liquidity adjusted portfolio. When considering the regional sample, we find no outperformance for both weighing methods in the bear period. ${ }^{4}$ Moving to the bull periods, we observe a totally different picture than

\footnotetext{
${ }^{4}$ We excluded the Australia sample as the number of companies is too low in order to obtain a trustworthy result.
} 
that of the bear periods. All portfolios have positive alphas, most of them being statistically significant. Especially in Asia, we observe very high alphas for both portfolio formation methods with approximately $10 \%$ premium per year. The results of the regional sample also reveal that the outperformance is even larger after excluding companies with low turnover on the stock exchange. Sample 3 of Table 5 presents the health-care portfolios by sub-industry. We find a significant outperformance on the pharmaceutical group in the total period and in the bull period, which is statistically significant regardless of the weighting method. The equally-weighted health care providers and services portfolio as well as the equipment and supplies portfolio outperform in the full period as well as in the bull period and tend towards displaying an outperformance in the liquidity-adjusted variant. All other alphas are not statistically significantly different to zero. These results prove that our findings of the previous analyses are neither driven by the method we apply to compile our portfolio nor by an investment strategy that cannot be applied in practice (as the stocks are not investable due to low turnover). In contrast, it shows that the outperformance of the health-care industry is really driven by the characteristics of the industry.

\section{Concluding Remarks}

The health-care industry is amongst the largest industries offering many opportunities for an investment globally. However, academic literature on this sector is scare. This paper is the first to analyze the global health care industry from various perspectives. By analyzing 3,680 companies from all over the world, we find a statistically significant outperformance of the sector on a global basis in a period starting in 2000 and ending in June 2015. In addition, our results prove that the companies from the health-care sector have a lower risk level than the market benchmark. After splitting the global portfolios into regional portfolios, we observe that the 
outperformance is driven by companies from the Americas and Asia and, if small companies are weighted equally, also from Europe. A second split into sub-industries reveals that the outperformance is strongest in pharmaceutical companies. However, if weighted equally, the health care equipment $\&$ supplies industry also reveals an outperformance. When splitting our sample into bull and bear market periods and analyzing the performance separately, we observe that the outperformance of the industry is driven by expanding markets and not by bear periods, as some might expect. This result is statistically significant on a global, regional and industry specific basis. Most financial studies analyze returns only on a USD basis. In addition to this standard approach, we analyze the health-care industry in Euro and show that on a risk adjusted basis, the results for an investor outside the USD area are different to those of a US investor but, nevertheless, the EUR investor can also achieve a significant outperformance.

Regarding an explanation for the observed phenomena as well as their possible persistence, we revert to demographic-economic argumentation. First, it is well-known that the population is growing globally while the share of older people is growing disproportionately faster. This is due to the worldwide trend towards a longer life expectancy (see e.g. National Institute on Aging (2011)). Second, the risk of developing most types of chronic diseases (like diabetes, cancer or arthritis) increases with age (see e.g. Yashin et al. (2016)). And third, the medical and economic progress in many economies makes it possible and affordable to prolong the lives of those suffering from these diseases for many years (see e.g. Bunker (2001)). This mechanism is steadily increasing the costs for health care in many countries and, on average, also the cash flows of the firms in this sector. These arguments are especially true for the Asian region as the population there has been growing enormously and the awareness of health-care provision is increasing there. 
The general trend towards more elderly people is valid worldwide and also can be prolonged in the future, as demographic projections show (National Institute on Aging (2011)). Given these considerations, the question may of why it is possible to achieve abnormal returns for such a long time still remains relevant. An argument supporting the corresponding finding may be that analysts face a hard challenge in forecasting the cash flows of a certain health-care company, which may be very risky, even if the development for the whole sector appears to be clear.

In summary, our results are of interest to investors as they reveal that there are several variables that have to be considered when investing in the health care industry. Most important are timing, regional focus, sub-industries and the effect of the location of the investor.

\section{Ethics statement}

This analysis is based entirely on publicly available data. Therefore, no specific ethical approval is required. 


\section{References}

Black, Fischer, 1993, Beta and return, The Journal of Portfolio Management 20, 8-18.

Bredthauer, Jeffery, Brian. Payne, Jiri Tresl, and Gordon Karels, 2015, Presidential parties, monetary regimes, and health care returns, Managerial Finance 41, 1059-1076.

Bunker, John P., 2001, The role of medical care in contributing to health improvements within societies, International Journal of Epidemiology 30, 1260-1263.

Carhart, Mark M., 1997, On persistence in mutual fund performance, Journal of Finance 52, 5782.

Dellva, Wilfred L., Andrea L. DeMaskey, and Colleen A. Smith, 2001, Selectivity and market timing performance of fidelity sector mutual funds, Financial Review 36, 39-54.

Fama, Eugene F., and Kenneth R. French, 1992, The cross-section of expected stock returns, The Journal of Finance 47, 427-465.

Fama, Eugene F., and Kenneth R. French, 1993, Common risk factors in the returns on stocks and bonds, Journal of Financial Economics 33, 3-56.

Fama, Eugene F., and Kenneth R. French, 1997, Industry costs of equity, Journal of Financial Economics 43, 153-193.

Fama, Eugene F., and Kenneth R. French, 2012, Size, value, and momentum in international stock returns, Journal of Financial Economics 105, 457-472.

Griffin, John M., 2002, Are the Fama and French factors global or country specific?, Review of Financial Studies 15, 783-803. 
Guirguis, Hany S., Joseph Onochie, and Harry Rosen, 2001, The post-offering performance of IPOs in the health care industry, Journal of Economics and Finance 25, 194-205.

Hong, Harrison, Walter Torous, and Rossen Valkanov, 2007, Do industries lead stock markets?, Journal of Financial Economics 83, 367-396.

Lesser, Kathrin, Felix Rößle, and Christian Walkshäusl, 2016, Socially responsible, green, and faith-based investment strategies: Screening activity matters!, Finance Research Letters 16, 171178.

Lintner, John, 1965, The valuation of risk assets and the selection of risky investments in stock portfolios and capital budgets, Review of Economics and Statistics, 13-37.

Mossin, Jan, 1966, Equilibrium in a capital asset market, Econometrica: Journal of the Econometric Society, 768-783.

National Institute on Aging, 2011, Global health and aging, Washington, DC, USA: National Institute on Aging, National Institutes of Health.

Newey, Whitney K., and Kenneth D. West, 1987, A simple, positive semi-definite, heteroskedasticity and autocorrelationconsistent covariance matrix, Econometrica, 703-708.

Nofsinger, John, and Abhishek Varma, 2014, Socially responsible funds and market crises, Journal of Banking \& Finance 48, 180-193.

Sharpe, William F., 1964, Capital asset prices: A theory of market equilibrium under conditions of risk, Journal of Finance 19, 425-442.

Trsel, Jiri, Brian Payne, and Gordon Karels, 2014, Health Care Investing: Is a Higher Dose of Health Care Good for the Portfolio?, Journal of Investing 23, 53-66. 
Yashin, Anatoliy I., Konstantin G. Arbeev, Liubov S. Arbeeva, Deqing Wu, Igor Akushevich, Mikhail Kovtun, Arseniy Yashkin, Alexander Kulminski, Irina Culminskaya, and Eric Stallard, 2016, How the effects of aging and stresses of life are integrated in mortality rates: insights for genetic studies of human health and longevity, Biogerontology 17, 89-107. 
Figure 1: 100 USD Investment in the health-care portfolio and the market benchmark

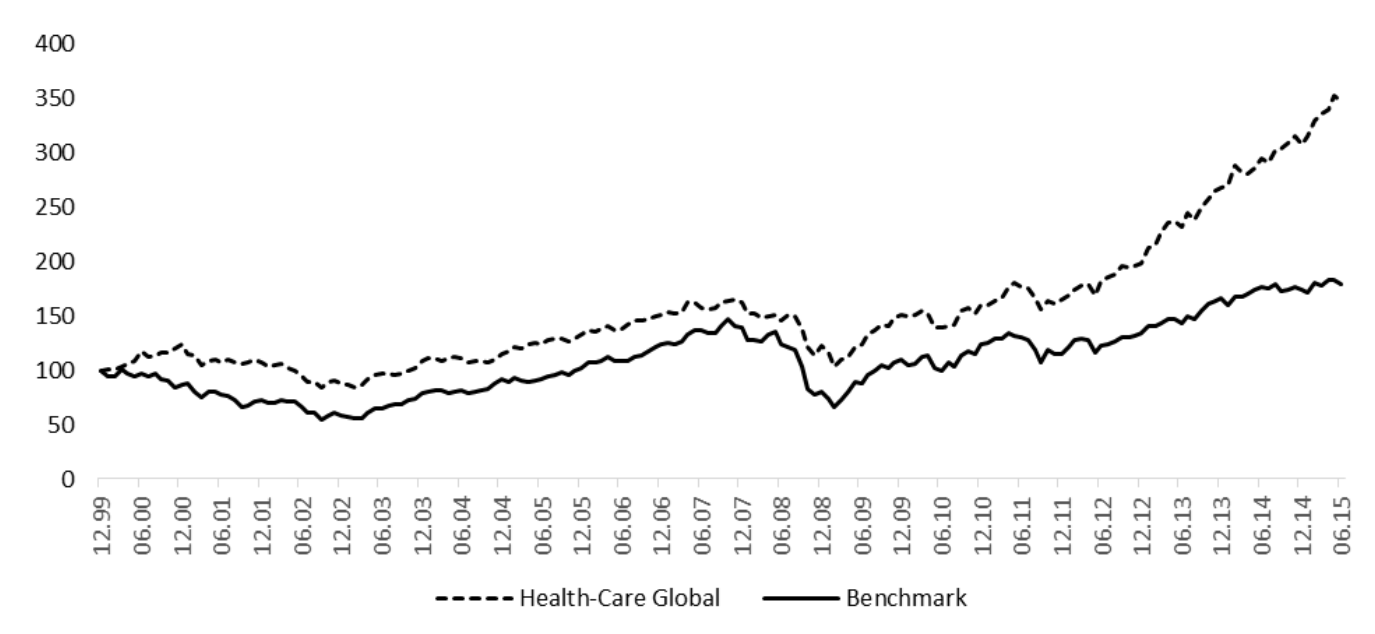

This figure illustrates the development of a $\$ 100$ investment in the value weighted health-care portfolio (dashed line) over the sample period from January 2000 through June 2015. For comparison, an investment in the market benchmark MSCI World (solid line) is included. 
Table 1: Summary statistics of the health-care portfolio

\begin{tabular}{llr}
\hline Figure & Unit & Result \\
\hline Firms & {$[\#]$} & 3,680 \\
thereof Dead Firms & {$[\#]$} & 160 \\
Return & {$[\%]$} & 0.73 \\
\hline
\end{tabular}

This table presents the summary statistics, with the total number of health care firms, the number of dead firms, and the average return. 
Table 2: Financial performance and firm characteristics of the health care industry

\begin{tabular}{|c|c|c|c|c|c|c|}
\hline & \# & Alpha & Beta & SMB & HML & WML \\
\hline \multicolumn{7}{|c|}{ Sample 1: Global } \\
\hline Global & 3680 & $\begin{array}{c}0.36 \\
(2.20)\end{array}$ & $\begin{array}{c}0.63 \\
(13.56)\end{array}$ & $\begin{array}{c}-0.19 \\
(-1.77)\end{array}$ & $\begin{array}{c}0.08 \\
(0.79)\end{array}$ & $\begin{array}{c}0.08 \\
(1.74)\end{array}$ \\
\hline \multicolumn{7}{|c|}{ Sample 2: Regions } \\
\hline Americas & 1466 & $\begin{array}{c}0.39 \\
(2.04)\end{array}$ & $\begin{array}{c}0.61 \\
(8.64)\end{array}$ & $\begin{array}{c}-0.13 \\
(-1.08)\end{array}$ & $\begin{array}{c}0.04 \\
(0.37)\end{array}$ & $\begin{array}{c}0.06 \\
(1.08)\end{array}$ \\
\hline Asia & 1267 & $\begin{array}{c}0.50 \\
(2.14)\end{array}$ & $\begin{array}{c}0.58 \\
(13.12)\end{array}$ & $\begin{array}{c}0.30 \\
(2.42)\end{array}$ & $\begin{array}{c}-0.06 \\
(-0.53)\end{array}$ & $\begin{array}{c}0.11 \\
(2.03)\end{array}$ \\
\hline Australia & 148 & $\begin{array}{c}0.27 \\
(1.03)\end{array}$ & $\begin{array}{c}0.78 \\
(18.14)\end{array}$ & $\begin{array}{l}-0.05 \\
(-0.35)\end{array}$ & $\begin{array}{c}0.20 \\
(1.11)\end{array}$ & $\begin{array}{c}0.07 \\
(0.98)\end{array}$ \\
\hline Europe & 702 & $\begin{array}{c}0.28 \\
(1.46)\end{array}$ & $\begin{array}{c}0.63 \\
(17.34)\end{array}$ & $\begin{array}{l}-0.18 \\
(-2.49)\end{array}$ & $\begin{array}{c}0.06 \\
(0.85)\end{array}$ & $\begin{array}{c}0.08 \\
(1.74)\end{array}$ \\
\hline \multicolumn{7}{|c|}{ Sample 3: Industries } \\
\hline $\begin{array}{l}\text { Biotechnology \& Medical } \\
\text { Research }\end{array}$ & 944 & $\begin{array}{c}0.15 \\
(0.30)\end{array}$ & $\begin{array}{c}0.95 \\
(7.63)\end{array}$ & $\begin{array}{c}2.28 \\
(3.18)\end{array}$ & $\begin{array}{c}-1.39 \\
(-2.63)\end{array}$ & $\begin{array}{c}0.58 \\
(2.41)\end{array}$ \\
\hline $\begin{array}{l}\text { Health care Equipment \& } \\
\text { Supplies }\end{array}$ & 984 & $\begin{array}{c}0.24 \\
(1.24)\end{array}$ & $\begin{array}{c}0.76 \\
(13.62)\end{array}$ & $\begin{array}{c}0.54 \\
(3.59)\end{array}$ & $\begin{array}{c}-0.08 \\
(-0.95)\end{array}$ & $\begin{array}{c}0.14 \\
(2.42)\end{array}$ \\
\hline Health care Providers \& Services & 524 & $\begin{array}{c}0.11 \\
(0.28)\end{array}$ & $\begin{array}{c}0.68 \\
(10.09)\end{array}$ & $\begin{array}{c}0.38 \\
(1.96)\end{array}$ & $\begin{array}{c}0.64 \\
(3.55)\end{array}$ & $\begin{array}{c}0.13 \\
(1.64)\end{array}$ \\
\hline Pharmaceuticals & 1228 & $\begin{array}{c}0.45 \\
(2.47)\end{array}$ & $\begin{array}{c}0.57 \\
(11.61)\end{array}$ & $\begin{array}{c}-0.50 \\
(-4.79)\end{array}$ & $\begin{array}{c}0.10 \\
(0.89)\end{array}$ & $\begin{array}{c}0.03 \\
(0.68)\end{array}$ \\
\hline
\end{tabular}

This table presents alpha estimates and portfolio characteristics based on the factor sensitivities obtained from regressing the monthly excess returns of the value weighted health-care portfolio on the explanatory factors of the four-factor model. Robust t-statistics derived from Newey and West (1987) standard errors are reported in parentheses. 
Table 3: Alpha estimates for Bull and Bear periods

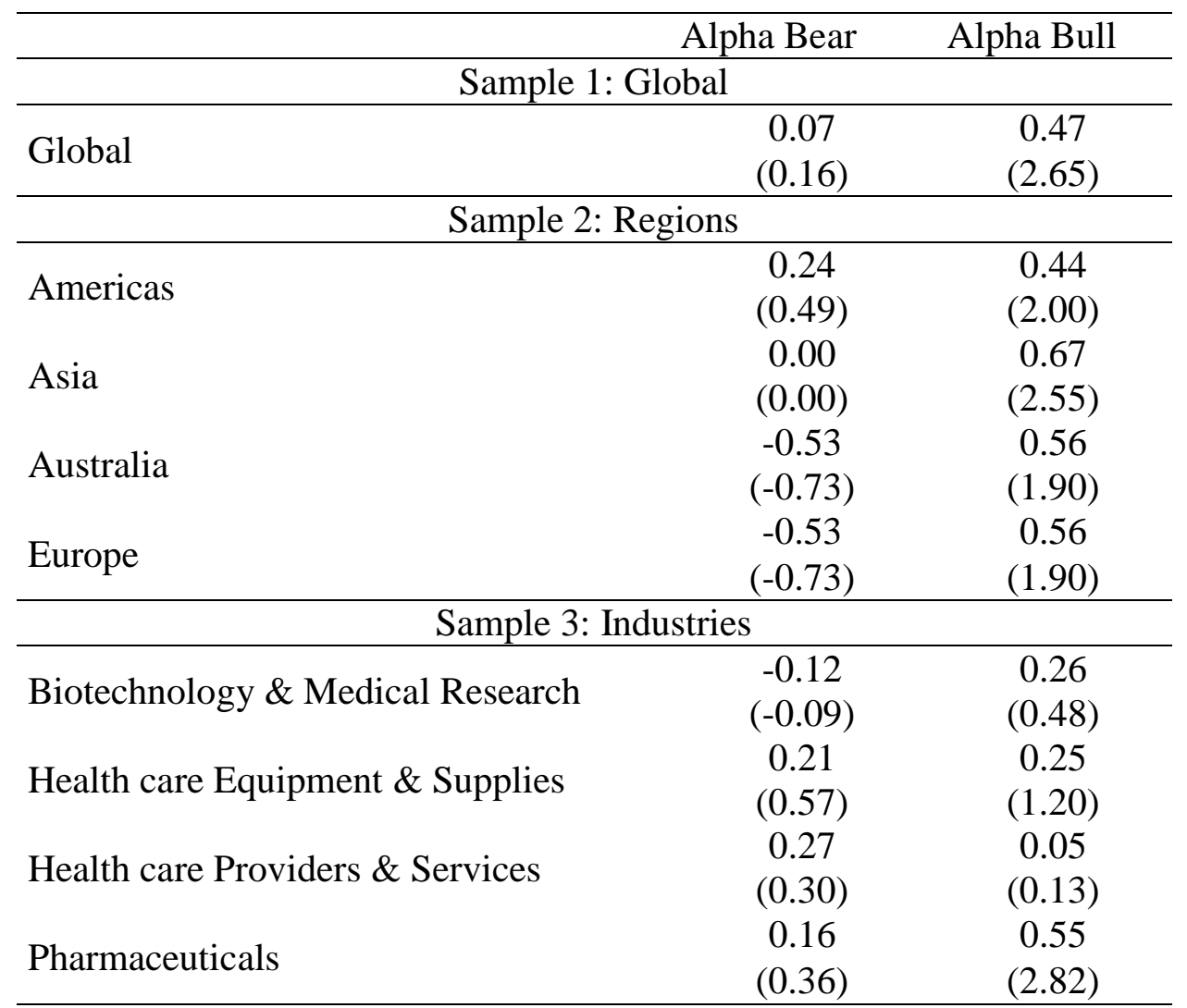

This table presents alpha estimates for the full period, as well as bull and bear periods obtained from regressing the monthly excess returns of the value weighted health-care portfolio on the explanatory factors of the four-factor model. Robust $t$-statistics derived from Newey and West (1987) standard errors are reported in parentheses. 
Table 4: Alpha Estimates for Bull and Bear Periods in Euro

\begin{tabular}{|c|c|c|c|}
\hline & Alpha & Alpha Bear & Alpha Bull \\
\hline \multicolumn{4}{|c|}{ Sample 1: Global } \\
\hline \multirow[t]{2}{*}{ Global } & 0.24 & -0.11 & 0.37 \\
\hline & $(1.35)$ & $(-0.25)$ & $(2.15)$ \\
\hline \multicolumn{4}{|c|}{ Sample 2: Regions } \\
\hline \multirow[t]{2}{*}{ Americas } & 0.28 & 0.12 & 0.33 \\
\hline & $(1.29)$ & $(0.23)$ & $(1.47)$ \\
\hline \multirow[t]{2}{*}{ Asia } & 0.48 & -0.03 & 0.64 \\
\hline & $(2.03)$ & $(-0.08)$ & $(2.46)$ \\
\hline \multirow[t]{2}{*}{ Australia } & 0.24 & 0.05 & 0.80 \\
\hline & $(0.93)$ & $(0.07)$ & $(2.62)$ \\
\hline \multirow[t]{2}{*}{ Europe } & 0.14 & -0.34 & 0.31 \\
\hline & $(0.75)$ & $(-0.66)$ & $(1.84)$ \\
\hline \multicolumn{4}{|c|}{ Sample 3: Industries } \\
\hline \multirow[t]{2}{*}{ Biotechnology \& Medical Research } & 0.60 & 0.37 & 0.68 \\
\hline & $(0.9)$ & $(0.26)$ & $(1.03)$ \\
\hline \multirow[t]{2}{*}{ Health care Equipment \& Supplies } & 0.35 & 0.33 & 0.36 \\
\hline & $(1.98)$ & $(0.93)$ & $(1.74)$ \\
\hline \multirow[t]{2}{*}{ Health care Providers \& Services } & 0.41 & 0.49 & 0.38 \\
\hline & (1.2) & $(0.52)$ & $(1.15)$ \\
\hline \multirow[t]{2}{*}{ Pharmaceuticals } & 0.19 & -0.15 & 0.32 \\
\hline & $(0.92)$ & $(-0.28)$ & $(1.56)$ \\
\hline
\end{tabular}

This table presents alpha estimates for bull and bear periods obtained from regressing the monthly excess returns of the value weighted health-care portfolio on the explanatory factors of the four-factor model. The calculations are based on portfolios in the currency Euro. Robust t-statistics derived from Newey and West (1987) standard errors are reported in parentheses. 
Table 5: Alpha estimates for bull and bear periods for equal-weighted and liquidity adjusted portofolios

\begin{tabular}{|c|c|c|c|c|c|c|}
\hline & \multicolumn{3}{|c|}{ Equally Weighted } & \multicolumn{3}{|c|}{ Liquidity } \\
\hline & Alpha & Alpha Bea & Alpha Bull & Alpha & Alpha Bear & Alpha Bull \\
\hline Global & $\begin{array}{c}0.43 \\
(2.17)\end{array}$ & $\begin{array}{c}0.15 \\
(0.27)\end{array}$ & $\begin{array}{c}0.53 \\
(2.61)\end{array}$ & $\begin{array}{c}0.44 \\
(2.41)\end{array}$ & $\begin{array}{c}0.14 \\
(0.30)\end{array}$ & $\begin{array}{c}0.56 \\
(2.72)\end{array}$ \\
\hline \multicolumn{7}{|c|}{ Sample 2: Regions } \\
\hline Americas & $\begin{array}{c}0.22 \\
(0.83)\end{array}$ & $\begin{array}{c}-0.30 \\
(-0.37)\end{array}$ & $\begin{array}{l}0.42 \\
(1.5)\end{array}$ & $\begin{array}{c}0.37 \\
(1.76)\end{array}$ & $\begin{array}{c}0.27 \\
(0.48)\end{array}$ & $\begin{array}{c}0.41 \\
(1.71)\end{array}$ \\
\hline Australia & $\begin{array}{c}0.19 \\
(0.66)\end{array}$ & $\begin{array}{c}-0.56 \\
(-0.73)\end{array}$ & $\begin{array}{c}0.45 \\
(1.65)\end{array}$ & & & \\
\hline Europe & $\begin{array}{c}0.66 \\
(3.03)\end{array}$ & $\begin{array}{c}0.93 \\
(1.53)\end{array}$ & $\begin{array}{c}0.57 \\
(3.29)\end{array}$ & $\begin{array}{c}0.27 \\
(1.03)\end{array}$ & $\begin{array}{c}-0.26 \\
(-0.43)\end{array}$ & $\begin{array}{c}0.45 \\
(1.68)\end{array}$ \\
\hline \multicolumn{7}{|c|}{ Sample 3: Industries } \\
\hline Health care Providers \& Services & $\begin{array}{l}0.38 \\
(1.3)\end{array}$ & $\begin{array}{c}0.01 \\
(0.01)\end{array}$ & $\begin{array}{c}0.52 \\
(1.67)\end{array}$ & $\begin{array}{c}0.39 \\
(0.84)\end{array}$ & $\begin{array}{c}0.17 \\
(0.13)\end{array}$ & $\begin{array}{c}0.47 \\
(1.39)\end{array}$ \\
\hline Pharmaceuticals & $\begin{array}{c}0.77 \\
(3.02)\end{array}$ & $\begin{array}{c}0.18 \\
(0.34)\end{array}$ & $\begin{array}{c}0.98 \\
(3.30)\end{array}$ & $\begin{array}{c}0.42 \\
(1.70)\end{array}$ & $\begin{array}{c}-0.13 \\
(-0.20)\end{array}$ & $\begin{array}{c}0.62 \\
(2.54)\end{array}$ \\
\hline
\end{tabular}

This table presents alpha estimates for the full period, as well as the bull and bear periods obtained from regressing the monthly excess returns of the health-care portfolio on the explanatory factors of the four-factor model. The portfolios are either equally weighted or adjusted for liquidity. Robust t-statistics derived from Newey and West (1987) standard errors are reported in parentheses. 